\title{
Dependence of Tin Whisker Growth on Copper and Oxygen Content on the Surface of Tin-Rich Lead Free Alloys
}

\author{
A. SkWAREK $^{a}, \mathrm{~K} . \mathrm{WiteK}^{b}, \mathrm{M} \cdot \mathrm{PluskA}^{c}$ AND A. Czerwinski ${ }^{c}$ \\ ${ }^{a}$ Institute of Electron Technology, Department of Microelectronics, Zabłocie 39, 30-701 Cracow, Poland \\ ${ }^{b}$ Institute of Electron Technology, Department of Implementation and Production \\ Zabłocie 39, 30-701 Cracow, Poland \\ ${ }^{c}$ Institute of Electron Technology, Department of Materials and Semiconductor Structures Research \\ al. Lotników 32/46, 02-668 Warsaw, Poland
}

\begin{abstract}
The introduction of lead-free technology into electronics has intensified concern over tin whiskers phenomenon. Tin whiskers are crystals growing from the alloy surface as the result of compressive stress relaxation. This paper presents the dependence of tin whisker growth on copper and oxygen surface content. The observations and measurements were done using scanning electron microscopy with energy-dispersive X-ray spectroscopy. The results show that whisker growth is strongly related to increased copper and oxygen surface content in whisker neighborhood.
\end{abstract}

DOI: $10.12693 /$ APhysPolA.123.430

PACS: 61.66.Dk, 68.70.+w, 68.37.Hk

\section{Introduction}

Soldering is one of the oldest processes known to mankind. The proper solder joint is created by producing the metallic bond between the soldered elements and solder. In the twentieth century, the most popular solder was Pb37Sn63 eutectics. From July 2006 the use of $\mathrm{Pb}$ in solders is banned in the European Union as a consequence of RoHS directive. Actually, most of the lead-free alloys is based on Sn containing in their composition also $\mathrm{Ag}, \mathrm{Cu}$, and the small additions of $\mathrm{Ni}, \mathrm{Co}, \mathrm{Ge}$ or $\mathrm{Sb}$. The introduction of tin-rich lead free solder has renewed the concern over, known for ages but limited by lead addition, phenomenon: tin whiskers. This phenomenon can significantly influence the reliability of solder connection and as a result influences the work of whole printed circuit board (PCB).

Tin whiskers are the crystals growing from the tin or tin alloy surface which can be dangerous for circuit reliability because of electrical current leakage and shorting due to bridging of adjacent conductors, metal vapor arcing (plasma) at low pressure, increased electromagnetic radiation, and damage from device littering by debris and contamination $[1,2]$. The growth of tin whisker is caused by the compressive stress relaxation [3]. The copper intermetallic compounds and surface layer of oxygen can strongly influence whisker growth.

This paper presents the results of EDS studies showing the relationship between tin whisker formation and copper and oxygen surface content in whisker neighborhood.

\section{Experimental}

To estimate the dependence of tin whisker growth on copper and oxygen surface content, the test samples were prepared using PCB technology. In the experiment the glass-epoxy laminates with a $\mathrm{Cu}$ foil of $17 \mu \mathrm{m}$ thickness were used. One part of the samples was prepared with an electroless $\mathrm{Ni}$ immersion Au sublayer, using a Pd activator. The Ni thickness varied from 4 to $6 \mu \mathrm{m}$ and the plated Au layer was about $0.05 \mu \mathrm{m}$. The conductive pads were covered with $\mathrm{Sn} 100$ and $\mathrm{Sn} 99.3 \mathrm{Cu} 0.7 \mathrm{Ni}$ solder alloy. The alloys were applied by hand soldering with water flux application. The soldering temperature was dependent on the alloy composition. The thickness of all Sn layers was in the range from $10 \mu \mathrm{m}$ to $20 \mu \mathrm{m}$. The samples were subjected to long-term exposure at temperature of $60^{\circ} \mathrm{C}$ and relative humidity $87 \% \mathrm{RH}$ for $3000 \mathrm{~h}$. Scanning electron microscope (SEM) images and energy-dispersive $\mathrm{X}$-ray spectroscopy (EDS) were performed with a Philips XL30 microscope. To determine the local content of elements - in particular copper and oxygen - X-ray spectra produced under the influence of the incident electron beam were performed in a scanning electron microscope. EDS analysis was performed for several points of the specimen: on the whisker body and on the whisker base. For the comparison purpose the same analysis was performed in the random places far from the nearest whisker, in the middle at the edge of solder pad.

The electron beam energy, used for EDS analysis, was at the level of $10 \mathrm{keV}$, so the penetration range of electrons in tin calculated according to the Kanaya-Okayama model for the $10 \mathrm{keV}$ is $0.65 \mu \mathrm{m}[4]$.

\section{Results}

For the samples exposed for $3000 \mathrm{~h}$ in $87 \% \mathrm{RH}$ and $60{ }^{\circ} \mathrm{C}$ whiskers were found on all four types of samples, i.e. on Sn100 and Sn99.3Cu0.7Ni soldered both directly on the $\mathrm{Cu}$ layer, as well as the $\mathrm{Ni} / \mathrm{Au}$ sublayer (Figs. 1, 2). 
However, they were found only at the edge of the solder (where the solder thickness is significantly smaller than typical) while not at the typical thickness of the solder.

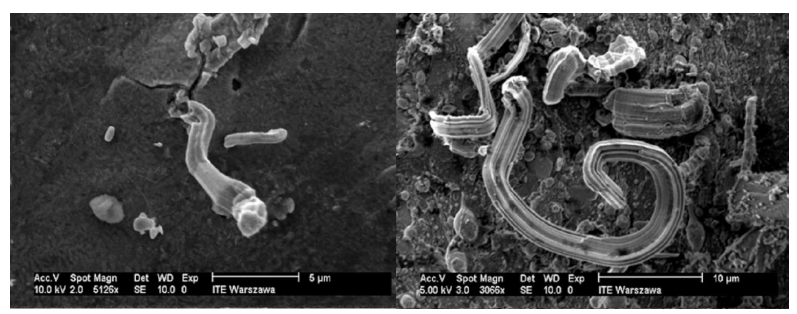

Fig. 1. SEM images of the samples soldered directly on $\mathrm{Cu}$ layer after $3000 \mathrm{~h}$ exposure at $87 \% \mathrm{RH}$ and $60{ }^{\circ} \mathrm{C}$ - the edge of the solder area. (A) Sn100, (B) $\mathrm{Sn} 99.3 \mathrm{Cu} 0.7 \mathrm{Ni}$.

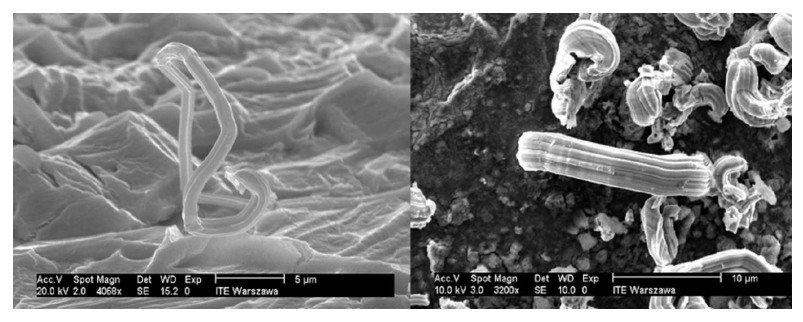

Fig. 2. SEM images of the samples soldered directly on $\mathrm{Cu}$ layer after $3000 \mathrm{~h}$ exposure at $87 \% \mathrm{RH}$ and $60{ }^{\circ} \mathrm{C}$ - the edge of the solder area.

\subsection{Copper content}

$\mathrm{Cu}$ content, measured directly on the whisker (found as mentioned earlier at the edge of solder pad) was amounted to $0.46 \mathrm{wt} \%$. This value can be regarded as negligible, because less than $1 \mathrm{wt} \%$ can be related to the EDS fluctuation signal. So it means that the whisker body was free from $\mathrm{Cu}$ content.

On the base of $70 \%$ of whiskers the copper content significantly increased - from 7.4 to $9.32 \mathrm{wt} \%$. At the base of $30 \%$ of whiskers the copper content was at the level of $1 \mathrm{wt} \%$. It does not mean, however, that at the base of the whiskers the increased copper content has not occurred. It may only mean that it was not detected by specific settings at the EDS studies. Namely, if on the way of the incident beam there is a whisker, then it partially covers the base against the electron beam and the precise measurement cannot be done.

No particularly distinguished copper content in the other areas of tin was noticed, regardless if the analysis was done at the edge or in the middle of the soldered pad.

\subsection{Oxygen content}

For measuring the oxygen content, the method including the elimination of surface contamination was used. This method involves measuring of the carbon content and the calculation of approximately constant dependence of oxygen on carbon content (which corresponds to their constant relation in the chemical compounds or in the conglomerate forming contamination of the sample). On this basis, it is possible to determine how much oxygen is associated with sample contamination and how much with tin oxides.

On the whisker body (found as mentioned earlier only at the edge of solder pad) the detected oxygen content was at the level of $2.3-3 \mathrm{wt} \%$. The oxygen content on the whisker base reached from 14 to 21 wt\%. For comparison, oxygen content on the alloy surface located in the middle of the pad was from 4.6 to 9 wt\%. Such a high oxygen content in the area of whisker base, is related to the formation of tin oxide. When the measured oxygen content exceeds $12 \mathrm{wt} \%$ it suggests the occurrence of $\mathrm{SnO}_{2}[5]$ and in lesser degree $\mathrm{SnO}$. The exemplary EDS spectra for $\mathrm{Sn} 99.3 \mathrm{Cu} 0.7 \mathrm{Ni}$ (with signals from contaminations removed), presenting the results described above, are shown in Fig. 3.

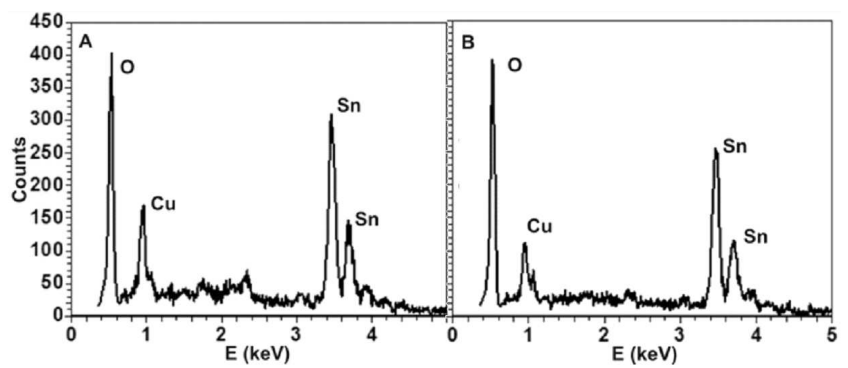

Fig. 3. EDS spectra of the samples of $\mathrm{Sn} 99.3 \mathrm{Cu} 0.7 \mathrm{Ni}$, after $3000 \mathrm{~h}$ exposure at $87 \% \mathrm{RH}$ and $60{ }^{\circ} \mathrm{C}$ soldered on (A) NiAu sublayer, (B) directly on $\mathrm{Cu}$ layer.

\section{Conclusions}

The increased copper content in the area of whisker base can be related to the presence of intermetallic compounds (in particular the presence of $\mathrm{Cu}_{6} \mathrm{Sn}_{5}$ ). The increased oxygen content is caused by the presence of tin oxides on the surface of the solder, particularly at such a high content of oxygen - the presence of $\mathrm{SnO}_{2}$. Both, increased copper and oxygen contents at the whisker base are strongly related to whisker growth.

\section{Acknowledgments}

This work has been supported by the National Science Centre under project no. N N515 503940.

\section{References}

[1] D. Pinsky, M. Osterman, S. Ganesan, IEEE Trans. Comp. Package Technol. 27, 427 (2004)

[2] G.T. Galyon, IEEE Trans. Electron. Package Manuf. 28, 17 (2005).

[3] K.N. Tu, Phys. Rev. B 49, 2030 (1994)

[4] K. Kanaya, S. Okayama, J. Phys. D, Appl. Phys. 5, $43(1972)$

[5] C. Chiavari, C. Martini, G. Poli, D. Prandstraller, J. Mater. Sci. 41, 1819 (2006) 